\title{
Controlled clinical trial for evaluation of hair growth with low dose cyclical nutrition therapy in men and women without the use of finasteride
}

\author{
Rajendrasingh Jalamsingh Rajput \\ Department of Hair Transplant \& Trichology, Dr Rajesh Rajput Hair Restore Clinic, Mumbai 400050, India.
}

Correspondence to: Dr. Rajendrasingh Jalamsingh Rajput, Department of Hair Transplant \& Trichology, Dr Rajesh Rajput Hair Restore Clinic, 201, Gasper Enclave, Pali Naka, Bandra west, Mumbai 400050, India. E-mail: drrajeshrajput@gmail.com

How to cite this article: Rajput RJ. Controlled clinical trial for evaluation of hair growth with low dose cyclical nutrition therapy in men and women without the use of finasteride. Plast Aesthet Res 2017;4:161-73.

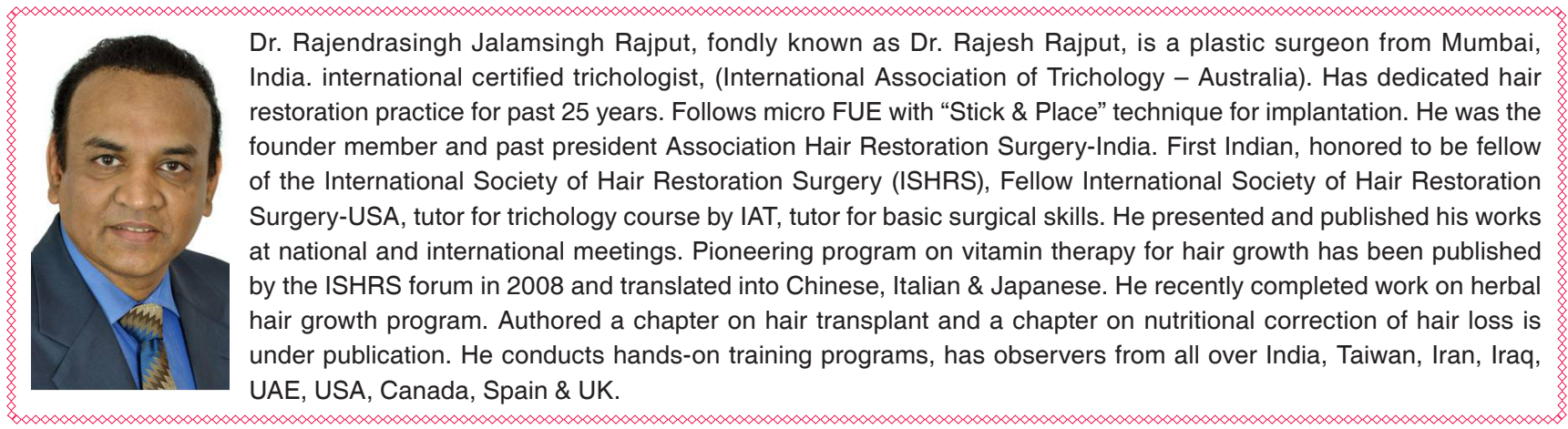

Article history:

Received: 23 Aug 2017

Accepted: 20 Sep 2017

Published: 30 Sep 2017

Key words:

Androgenic alopecia,

finasteride,

minoxidil,

cyclical vitamin,

hair nutrition,

\section{ABSTRACT}

Aim: To evaluate possible results with the stimulation use of minoxidil and the strengthening of hair roots with nutritional cyclical supplements, resulting in increased hair regrowth, without the use of anti androgens and enzyme blockers. Methods: This prospective controlled clinical trial compares the current acknowledged form of treatment for hair loss within two controlled groups for both men and women against the use of cyclical nutritional therapy and minoxidil $2 \%$. One hundred patients in each of the 4 groups, a total of 400 patients, were followed for 1 year. The progress was evaluated every 2 months with computerised measurements of hair density, hair calibre, global photography and uniquely designed self-assessment scores. Results: The use of nutritional supplements showed consistent improvements in both treatment groups of men and women against the controlled groups with a correction of hair fall and minimum $18 \%$ increased density within 2 months with further improvement to a maximum of

cc) () 9 (2) This is an open access article distributed under the terms of the Creative Commons AttributionCC) $\mathrm{BY}$ NC SA NonCommercial-ShareAlike 3.0 License, which allows others to remix, tweak, and build upon the work non-commercially, as long as the author is credited and the new creations are licensed under the identical terms. 
trichoscopy,

hair growth,

hair loss,

side effects,

cyclical therapy
156\% over 1 year. Conclusion: Hair loss occurs when weak, sensitive, follicles are affected by multiple causes. Hair regrowth can be achieved consistently and safely by strengthening the hair roots and promoting hair growth without necessarily depending on the use of anti androgens.

\section{INTRODUCTION}

Today, with the understanding of teloptosis and kenogen by Guarrera et al. ${ }^{[1-3]}$, patients develop baldness, not due to hair loss but due to the empty follicle stage. Patients gradually develop empty bald areas as a result of the falling telogen hair no longer being replaced with new anagen hair. The physiological balance of the hair growth cycle is disrupted ${ }^{[3-6]}$ leading to loss of density, gradually manifesting into baldness. However, patients assume they are balding due to the visual hair loss and pursue multiple remedies for control. The loss of 100-150 hair follicles a day is normal ${ }^{[7,8]}$ in Caucasians. Caucasians have over a 100,000 hair follicles on the head and losing 150 follicles a day, or 4,500 in a month, is a loss of less than $5 \%$. We would draw attention to the fact that, even after considering individual variation in the total number of follicles lost, there would remain $85 \%$ to $95 \%$ of follicles which are not in the active fall phase - these follicles are available and willing to grow. How can we make these follicles grow better and healthier? Let us look at the available knowledge in a new perspective to promote hair growth and achieve better density instead of fighting hair fall.

Various factors affecting hair loss, weaken the hair roots and make them sensitive to normal levels of androgens in the body ${ }^{[9-12]}$. Pattern hair loss can occur with normal androgen levels ${ }^{[12,13]}$, pattern hair loss can occur before puberty ${ }^{[13-15]}$, it has been reported in hypogonadism ${ }^{[16]}$ and also in a case of complete androgen insensitivity syndrome ${ }^{[17]}$. Instead of insisting on anti-androgens in management of hair loss patients, we should focus on strengthening the hair follicle and promoting better hair growth to ensure more hair on the head. Eminent research workers Trueb ${ }^{[3]}$, Klingman ${ }^{[4]}$, Rook and Dawber ${ }^{[5]}$ in their studies of the dynamics of hair growth, have highlighted the fact that hair loss is a result of dysregulation of the hair growth cycles or imbalance between factors regulating, hair loss and hair growth or to say the factors known to be, favourable and unfavourable for hair growth. The same is also emphasised by the studies of Headingto ${ }^{[6]}$, Paus and Cotsarelis ${ }^{[7]}$, Liyanage and Sinclair ${ }^{[8]}$. The role of dihydrotestosterone (DHT) levels in hair loss is being questioned ${ }^{[18]}$. Research and understanding today suggest that hair loss can be genetic, hormonal, nutritional, inflammatory or due to altered immunity ${ }^{[11,19-22]}$.

Research workers have attributed the thinning and miniaturization of the hair as the hallmark of androgenic alopecia (AGA). Now numerous other types of thinning and hair loss have been identified as mimicing $A G A^{[22-25]}$. Therefore we found the need to develop a new category of description and classification defined as diffuse unpatterned hair loss (DUPA) $)^{[8,26]}$. We now clinically face hair loss that displays all the characteristics of AGA but does not confirm to genetic predisposition and has no family history ${ }^{[27]}$. AGA can skip siblings and skip generations. Though siblings carry the genes, there are more collaborators than just the presence of DHT to manifest miniaturization and present the clinical characteristics of AGA. Works of Headington, Philpott, Farjo N, Farjo B and Bahta have indicated that the multiple pathways of hair loss are in fact, interlinked, overlapping and in over $33 \%$ of the cases there may not be any identifiable cause ${ }^{[6,28]}$.

DHT has been considered to be a cause for hair loss but it is uncommon to find raised DHT levels in patients and there is no correlation between DHT levels and the grade of hair loss manifested in the patients ${ }^{[18]}$. Under the influence of other known and unknown factors, even normal androgen levels can lead to hair loss. DHT's presence is what causes the genes to express the balding gene and the blood levels alone do not relate directly to the extent of hair loss. Thus we say, not a raised DHT but a higher sensitivity of the hair roots is responsible for hair loss ${ }^{[11,29-31]}$. Studies by Sawaya and Price ${ }^{[32]}$, on the 5-alpha reductase type 1 , type 2, aromatase and androgen receptors, along with the cutaneous androgen metabolism studies by Chen et al. ${ }^{[33]}$ and Hoffman and Happle ${ }^{[34]}$ current understanding of androgenic alopecia, all support the conclusion that sensitivity of the follicles is of greater concern than raised levels of androgens. We have discovered a limited correction of one of the mechanisms for hair loss by blocking conversion of testosterone to DHT but are attempting to treat all the various types of hair loss with the same approach. Minoxidil and finasteride, which to date are the only two FDA approved and commonly accepted treatments for hair loss, were both discovered by serendipity and not by studying the hair loss cycles. Patients treated with minoxidil do not always show a predictable standard 
response. Similarly patients treated with finasteride do not always show the same predictable responses ${ }^{[35-36]}$, some patients do not respond definitively. Reports by Kaufman et $a{ }^{\left[{ }^{[37]}\right.}$ in their long term finasteride study have reported that $17 \%$ patients have deteriorated during their treatment with finasteride.

\section{Hypothesis and the proposed perspective}

There are numerous causes for hair loss - these cannot be isolated as singularly responsible, but most of the times are working in tandem. We propose that the approach of cause based on treatment planning does not work for hair loss. The causes are vague, not quantifiable; are not measurable by any yardstick; and they cannot be confirmed to have a direct cause and effect relationship with hair loss. A group of people exposed to the same cause do not suffer the same kind of hair loss, if you try to treat one cause, hair roots being sensitive may fall prey to hair loss from another cause. We should consider the fact that the androgens or DHT levels in most hair loss patients are normal and not raised ${ }^{[18,23,24]}$. There are several persons with similar androgen levels who do not have any hair loss at all. As well as there are other persons who carry the genes, passing them off to the next generation, who do not themselves, manifest any hair loss symptoms. There are several persons losing hundreds of hair per day but not going bald because their fallen hair is regularly replaced with new hair, as the hair cycle continues $^{[1-3]}$. Focus should be on the promotion of hair growth cycles and not on fighting the androgens. The anti-androgenic treatments are required to be used for a long periods of time, possibly even lifelong. Recent studies by Irwig ${ }^{[38]}$ and Traish et al. ${ }^{[39]}$ highlight the point that long term use of anti-androgens increases the possibility of negative side effects that may also be irreversible. Therefore, it is more scientifically beneficial to strengthen the hair roots, provide a toxin free environment for the cells and promote hair growth rather than trying to treat a suspected causes that cannot be confirmed. Strengthening the hair and promoting growth can be achieved with vitamins, minerals and nutritional supplements which will deliver wellness, good health as well as hair growth. The falling hair originates from the gradual weakening of the natural available stock hair roots on the scalp, if these are made strong, the basic source from which falling hair is generated will be blocked preventing further hair loss. In a sense it would reduce the number of hair falling in every cycle.

\section{DHT can be blocked by antioxidants}

An initial experimental study by Eun ${ }^{[40]}$ discovered that DHT does not directly cause inhibition of hair growth but it induces the release of transforming growth factor beta 1 (TGFß1) which results in the miniaturization and hair loss. Shin et al. ${ }^{[41]}$ followed this research further with cultured androgen sensitive dermal papilla cells and the addition of DHT to this androgen sensitive cell caused an accumulation of free radicles ROS within the cultured cells, which in turn induced the release of TGFß1. The next step of the study was the addition of free radical scavenger N-Acetyl cysteine to the cell culture, that successfully blocked the accumulation of free radicals resulting in successful blockage of DHT induced secretion of TGFß $1^{[41]}$. Therefore, we can consider now that antioxidants can prevent accumulation of free radicals or reactive oxygen species which in turn can neutralize the mechanism of the action of DHT. Vitamin D has direct action on induction of hair growth from the dermal papilla. The role of oxidative stress ${ }^{[42]}$, nutrients, vitamins ${ }^{[43]}$, minerals ${ }^{[44,45]}$, amino acids in maintaining immunity, preventing micro inflammation ${ }^{[46,47]}$, and promoting hair growth has been discussed by several research scientists. The details of the role of non-androgenic factors have previously been published ${ }^{[48]}$.

Due to the long term practical use of a hair care program, a more natural alternative solution is desirable. Cellular turnover and metabolic activity in the hair follicles is equivalent to bone marrow and intestinal epithelium therefore, hair growth requires multiple nutrients: antioxidants, amino acids, vitamins, minerals and fatty acids ${ }^{[49]}$. While studying the nutrients it was highlighted that use of too many supplements at a time, can interfere with the absorption and efficiency of one another. Iron and calcium, given together can chelate each other and reduce the absorption ${ }^{[50]}$. Regular intake of iron can create mucosal blocks to iron absorption ${ }^{[51]}$, while excess iron can become pro oxidant through Fenton reaction ${ }^{[52,53]}$. Excess cellular calcium can induce apoptosis of the cells ${ }^{[54]}$. High intake of vitamin $\mathrm{C}$ does not ensure higher levels in circulation $^{[5]}$. High intake of antioxidants reverses the benefit and makes them behave as pro oxidants ${ }^{[56]}$. Details of such interaction have been discussed in our previous published study ${ }^{[49]}$.

High protein consumed in diet is ultimately digested to amino acids that enter the circulation, creating a surge that makes the blood $\mathrm{pH}$ acidic. The high acidity requires to be buffered immediately to maintain homeostasis. Physiologically, calcium is the best buffer system in the body. High blood acidity, causes reabsorption of calcium to buffer the acidic blood, leading to high calcium levels in the circulation. Kidneys recognise the excess calcium and begin excreting the calcium leading to a loss of calcium ${ }^{[57-60]}$ - ultimately causing weakening of hair and bone resulting in hair loss instead of hair growth. We found hair is an 
unusual organ that grows when cells in the body are allowed to die. Hair is created when the piling up of dead keratinized cells are serially pushed upwards while new dead cells are generated from below. Keratin deposition in the cells gradually increases as the cells are pushed towards the outer layers of the skin, finally the cells become non-viable, dead cells pile up over one another and are pushed out of the body in the form of hair and nails. Saturation of the body with vitamins, especially vitamin $A^{[61,62]}$, vitamin $E^{[63-65]}$, Omega three fatty acids ${ }^{[66]}$ become pro oxidant, interfere with keratinisation leading to non-creation of hair keratinized cells ultimately manifesting as hair loss instead of hair growth.

It should be highlighted that the recommended daily allowance (RDA) of various nutrients was decided by a discussion and consensus between random selected committees to meet requirement of the rations supplied to soldiers and industrial workers rather than by following experimental analysis of the metabolic requirements within the human body ${ }^{[67]}$. Nutrients and vitamins have two kinds of doses. A therapeutic dose given to patients suffering disease due to deficiency of the selected nutrient - which does is very high. A prophylactic or preventive dose to promote good health that can be as low as possible ${ }^{[68]}$. Part of the nutrients could come through diet while part via a low dose supplement.

\section{Aims and objectives}

To test the hypothesis that stimulation of hair growth and supporting cell division with nutritional supplements can result in hair growth, without the need to use antiandrogens or enzyme blockers in both men and women.

\section{METHODS}

\section{Patient selection}

Male and female patients between the ages of 25 to 50 years, requiring treatment for hair loss, were explained the nature of the study. Patients made their choice to have treatment with finasteride and minoxidil or follow minoxidil with the low dose once in 3 days supplement program. A total 400 patients $(200$ men and 200 women) agreed to choose the standard therapy or accept the nutritional therapy for a commitment of 1 year, were selected to form the control group and the treatment group with a total of 100 patients per group. The age distribution of male and female patients in the study is displayed in Table 1. We have attempted to have patients with comparable age and comparable grades of hair loss in the control groups and treatment groups as displayed in Tables 1-3.
Exclusion criteria: (1) patients who had previously tried any kind of hair loss treatment within the last 6 months, were excluded; (2) patients who were on any kind of supplements, protein shakes, medical treatment for any condition were excluded; (3) patients with regular alcohol intake and smokers were excluded; (4) male patients with Norwood Hamilton grade I and grade II hair loss and female patients with Ludwig grade I hair loss were excluded.

Control group for men (CM) and control group for women (CW): CM consisted of 100 volunteer male patients who were between 25 to 50 years of age and had hair loss between Norwood Hamilton grade III to grade V. The male control group received $1 \mathrm{mg}$ finasteride every day and application of $2 \%$ minoxidil lotion 2 times a day, $1 \mathrm{~mL}$ in the morning after bath and $1 \mathrm{~mL}$ in the evening before sleep every day.

Control group for women consisted of 100 volunteer female patients who were between 25 to 50 years of age and had hair loss Ludwig grade II and III. The female control group did not receive finasteride, but were prescribed the application of $2 \%$ minoxidil lotion $1 \mathrm{~mL}, 2$ times a day, morning after bath and evening before sleep.

Treatment group for men (TM) and treatment group for women (TW): Treatment groups for both men and women followed the same protocol. Patients in both the groups did not receive finasteride. Both men and women treatment group applied $2 \%$ minoxidil lotion $1 \mathrm{~mL}, 2$ times a day, morning after their shower/bath and again in the evening prior to sleep. In addition, they received nutritional supplements which included antioxidants, vitamins, minerals, omega 3 , amino acids and biotin. In order to avoid inter nutrient interactions, improve absorption and have better efficiency we planned to have these supplements in synergistic combinations over a 3 day cycle [Table 3].

Method of hair care and use of nutritional supplements

Table 1: Age distribution of the patients in the study, (\%)

\begin{tabular}{lcc|}
\hline Age (years) & Male & Female \\
\hline $25-30$ & 32 & 36 \\
$30-40$ & 47 & 40 \\
$40-50$ & 21 & 24 \\
\hline
\end{tabular}

Table 2: Grade of hair loss in male patients, (\%)

\begin{tabular}{lcc}
\hline & Control group & Treatment group \\
\hline Grade III & 30 & 32 \\
Grade IV & 50 & 48 \\
Grade V & 20 & 20 \\
Ludwig II & 48 & 46 \\
Ludwig III & 52 & 54 \\
\hline
\end{tabular}


We developed a 3 day cycle to utilize 6 supplement formulations, in combinations that do not interfere with the efficiency of one another and could be synergistic in action. The patients also felt that they were not taking too many medicines at one time - a simple 2 per day. Patients who had a light or no breakfast were permitted to have the supplements after lunch. Patients who felt heaviness in the stomach could take 1 supplement after lunch and one after dinner. All patients applied minoxidil $2 \% 1 \mathrm{~mL}$ in the morning and $1 \mathrm{~mL}$ in the evening every day.

\section{Scalp hygiene}

All patients in all groups were advised regular shampoo 3 times a week. Removing dirt, grime, scalp secretions were considered important in facilitating better hair growth.

\section{Evaluation of hair regrowth by global photography}

All patients had standard photographic views with a 12 megapixel digital camera in a fixed, designated place with identical settings, the same light, same flash, same distance and same camera. Photographs were taken at day 1 , then every 2 months to record the progress for 1 year. Before and after photographs taken, in 5 standard views as front hairline, vertex with head bent forward, right side, left side and occipital whorl area. Analysis of the photographs were done by 4 different evaluators who were blind to the patient profile and patient group. The criteria selected in order to evaluate in the photographs, were hair quality, hair density or fullness, reduction of bald area and new hair growth. The improvement was graded from grade I to grade $\mathrm{V}$ as I - no change, II - marginal change or barely noticeable change, III - noticeable improvement, IV - good improvement and V - very good improvement.

\section{Evaluation of hair density and calibre by computerized analysis}

All patients had computerized folliscope analysis for measurement of hair density and calibre at micro pigment tattooed, fixed test spots over their perceived area of thinning which was their selected area of most concern. With the computerized folliscope analysis we measured hair growth in terms of density per square centimetre and hair calibre in microns. The counts and calibre were recorded on day one and repeated every 2 months for the 1 year period of study.

\section{Villus hair count}

Villus hair counts were recorded initially and compared over 2-month intervals for 1 year. The attempt was to correlate if such a method allows to determine the conversion of villus hair to terminal hair during the treatment period.

\section{Self-evaluation}

Patients also had a self-evaluation score at the end of 1 year. Self-assessment score were designed to record the personal response of the patients within the study. Scores were allotted to control of hair loss, appearance of new hair growth, change is the size of the bald spot and difference noticed by friends and family. Zero score was allotted for no change and negative score for deterioration of the area. An assessment score of 4 was satisfactory and 5 was considered good. A score of 3 was average and below 3 was considered poor [Table 4].

Patients were inquired about sexual side effects, loss of libido, decreased volume of semen, softer erections, gloomy feeling and difficulty to focus on the task or the feeling of disinterest. Patients were requested to report any other concerns, as number of hair falling per day, dandruff or itching.

\section{RESULTS}

\section{Reduction of hair fall}

In both the treatment groups TM and TW $68 \%$ patients reported reduction in hair fall per day within 1 month of commencing the therapy. By the end of 4 months $85 \%$ patients reported reduced hair loss. The average improvement did not improve further than $85 \%$ till the end of the study period of 1 year. Result being statistically significant with $P$-value 0.019 . The remaining $15 \%$ patients said the hair loss continued to be the same, though it has not increased. In both the control groups $\mathrm{CM}$ and $\mathrm{CW}$, hair fall continued

Table 3: Cyclical vitamin therapy low dose once in three days, have one each after breakfast odds ratio, one each after lunch odds ratio, one after lunch and one after dinner

\begin{tabular}{lc}
\hline Days of the week & Supplement combinations \\
\hline Monday \& Thursday & Antioxidant, calcium, vitamin D3, magnesium \\
Tuesday \& Friday & Iron, folic acid, vitamin C \& omega 3 \\
$\begin{array}{l}\text { Wednesday \& Saturday (Sunday - no medicines) } \\
2 \% \text { Ketoconazole \& zinc pyrithione shampoo }\end{array}$ & Essential aminoacids, B - complex \& biotin \\
$\begin{array}{l}\text { Wet your hair, massage the shampoo into the scalp, keep for } 3 \text { min \& wash, once in 3 - days } \\
\text { Minoxidil } 2 \% \text { solution }-1 \mathrm{~mL} \text { morning \& } 1 \mathrm{~mL} \text { evening - everyday }\end{array}$ \\
\hline
\end{tabular}


Table 4: Patient's self-assessment scores, min 0 to $\max 5$

\begin{tabular}{lc}
\hline Criteria & Score \\
\hline Area has become worse than before & -1 \\
Area looks the same & 0 \\
Hair loss is under control & 1 \\
Area looks better than before & 1 \\
Area is showing new hair growth & 1 \\
Area of hair loss has become smaller than before & 1 \\
Friends and others are noticing the difference & 1 \\
\hline
\end{tabular}

unabated all through the study period in $41 \%$ patients having no relief. At the end of 4 months $22 \%$ patients reported that they had some relief from hair fall, while $37 \%$ patients insisted their hair fall had increased despite being on treatment.

\section{Density and calibre}

Group TM showed $18 \%$ average improvement in density at 2 months and $30 \%$ and at 4 months. All patients responded with variable improvement in density and calibre. The average improvement in calibre in 2 months was $9 \%$ and at 4 months was $21 \%$ [Figure 1]. As the follow-up continued beyond the first 4 months cycle, the patients in the treatment group TM had 51\% improvement in hair density at 6 months and $76 \%$ improvement at the end of 1 year [Figure 2]. The results were statistically significant with $\mathrm{P}$-value 0.00057 . One patient showed a maximum of $156 \%$ further improvement in hair density by 1 year
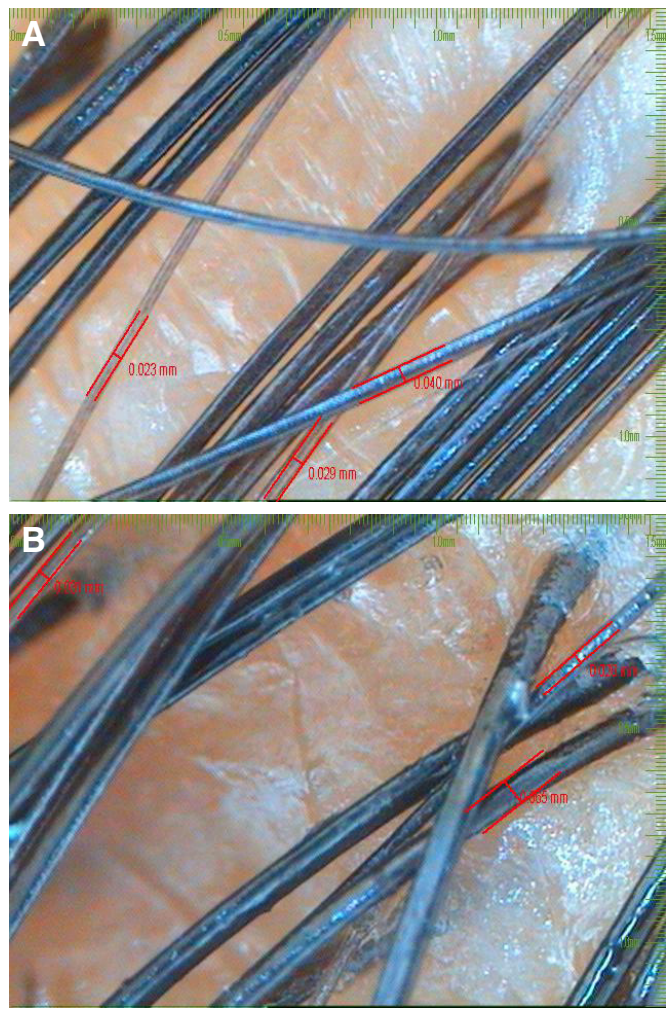

Figure 1: A: hair calibre folliscope measurement before; B: computerized folliscope measurement of hair calibre after 4 months
[Figure 3]. Patients with thinning in the crown area also responded well to cyclical medicine [Figure 4]. The additional improvement in hair calibre was $24 \%$ at 6 months which raised to $63 \%$ by the end of 1 year.

Group TW, female patients on cyclical medicine showed an average $20 \%$ improvement in density at 2 months and $36 \%$ at 4 months [Figure 5]. All patients responded with variable improvement in density and calibre. The improvement in calibre was on average $10 \%$ in 2 months and $25 \%$ in 4 months. As the follow-up continued beyond the first 4 months cycle, the patients in the treatment group TW had $41 \%$ improvement in hair density at 6 months and $70 \%$ at 1 year [Figures 5B and 6A]. The results were statistically
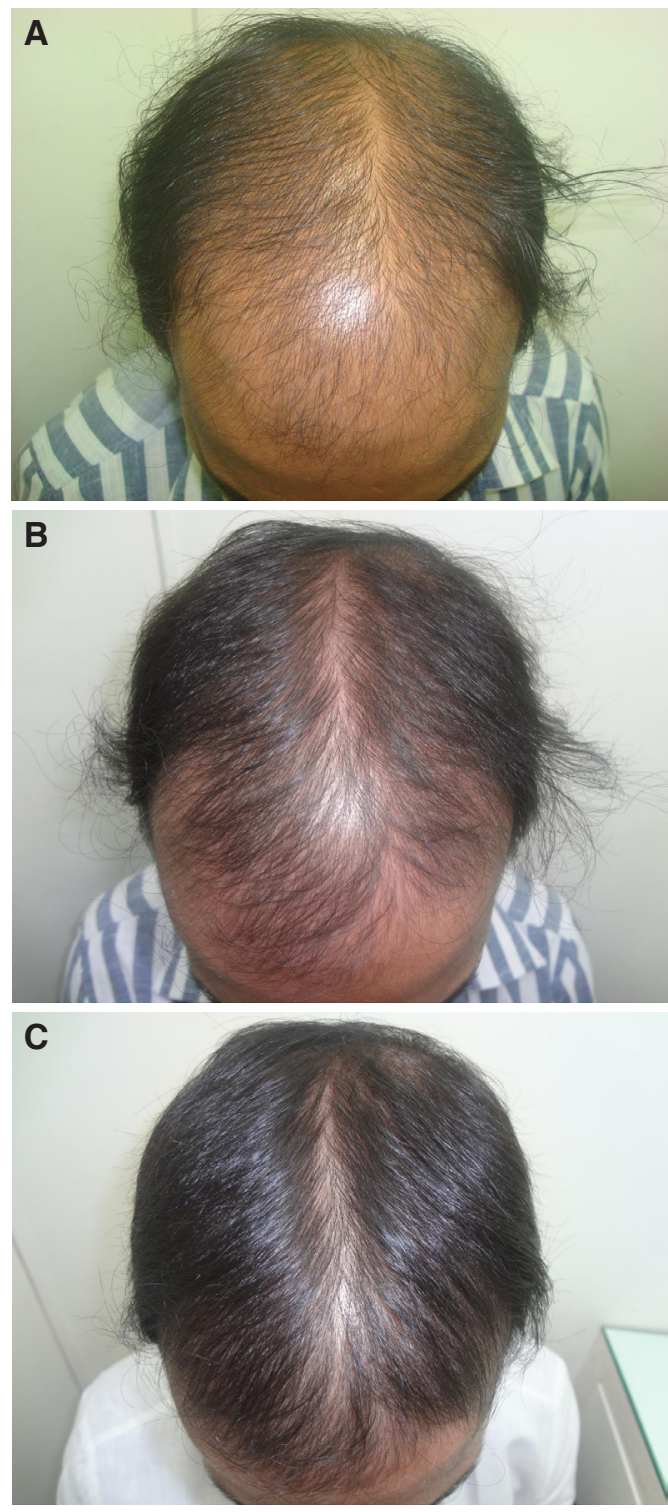

Figure 2: A: grade $\mathrm{V}$ baldness day one before starting treatment $\mathrm{B}$ : improvement after 2 months of nutritional correction and $2 \%$ minoxidil; C: regrowth in grade $\mathrm{V}$ baldness in 6 months without finasteride 


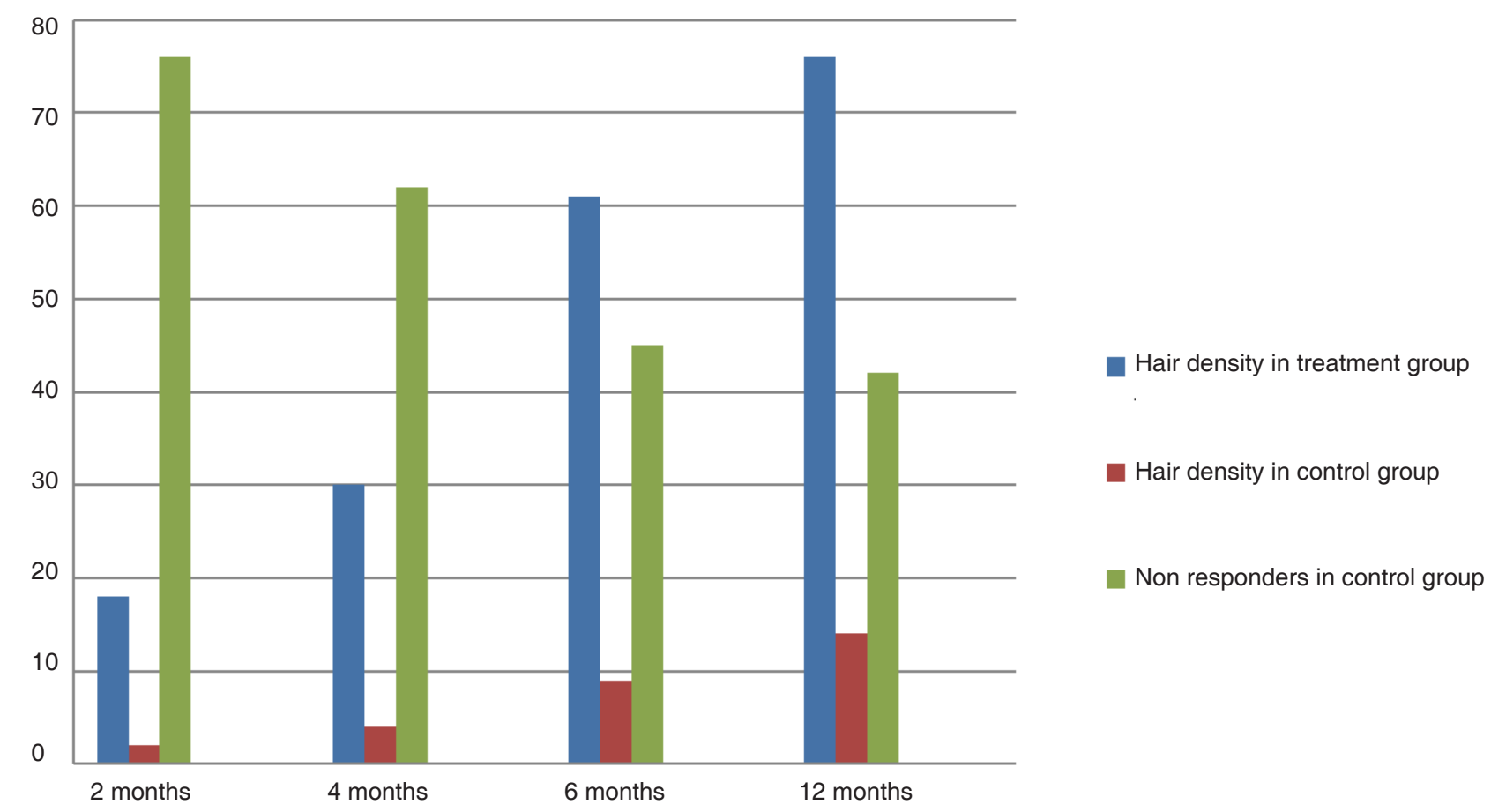

Figure 3: Hair density in men

significant with $P$-value 0.00038 . Patients with temporal angle receding and thinning also responded well to cyclical medicine [Figure 7]. Maximum improvement in hair density in 1 of the women was $112 \%$. Improvement in hair calibre was $33 \%$ at 6 months and $58 \%$ by the end of 1 year [Figure 8].

In the control group CM for men, $76 \%$ patients had no response in the initial 2 months and $62 \%$ had no response even at 4 months with $2 \%$ minoxidil and $1 \mathrm{mg}$ finasteride every day. The density improved by an average $2 \%$ at 2 months and $4 \%$ at 4 months. Hair calibre measured on folliscope, was $2 \%$ better at 2 months and $3 \%$ at 4 months. There were $48 \%$ patients having no improvement at all in either density or calibre at the end of 4 months. At 6 months the average improvement in density was $9 \%$ and the average calibre improved by $7 \%$. At 1 year, the hair calibre had improved $11 \%$ while at the end of 1 year the maximum density had improved $14 \%$. There were $45 \%$ patients with no change in density or calibre at 6 months - this number was reduced to $42 \%$ nonresponders at the end of 1 year.

In the control group CW for women, density improved by $3 \%$ in 2 months and $4 \%$ in 4 months, $56 \%$ females had no improvement at all at 2 months. Density improved by an average of $1.5 \%$ in 2 months and $3.5 \%$ in 4 months. Calibre was unchanged in $60 \%$ patients, it was $2 \%$ better at 2 months and $3 \%$ at 4 months, with $38 \%$ patients still having no improvement at all in density or calibre. At 6 months, the average
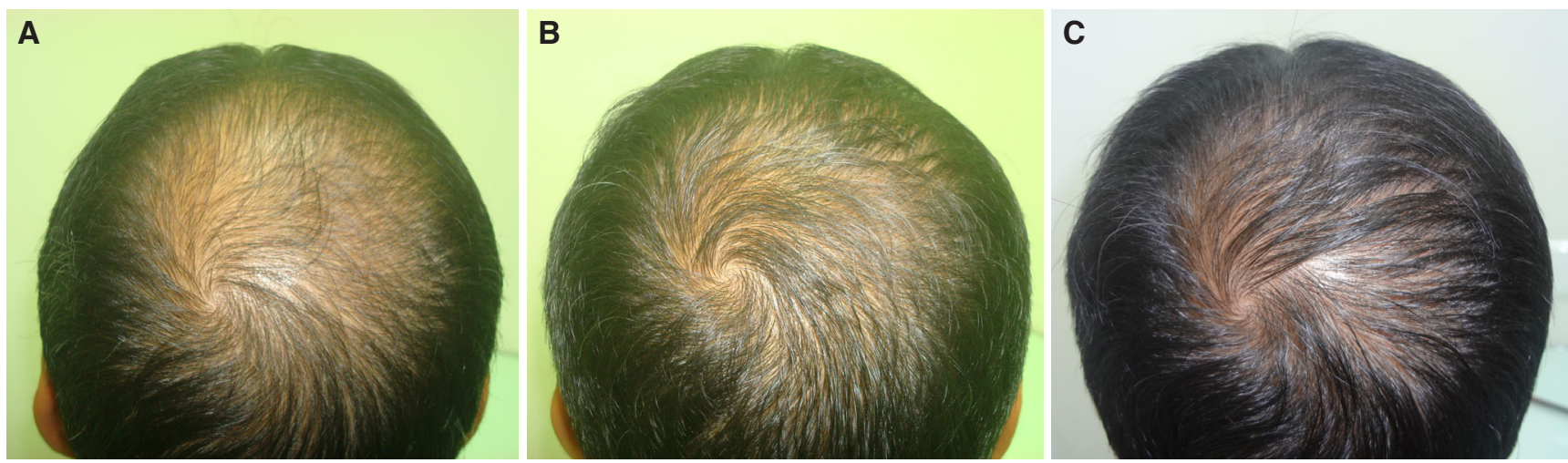

Figure 4: A: crown area grade $\mathrm{V}$ baldness day one before starting treatment; $\mathrm{B}$ : improvement over crown area after 2 months of nutritional correction and $2 \%$ minoxidil; C: regrowth in grade $\mathrm{V}$ baldness over crown area in 6 months without finasteride 

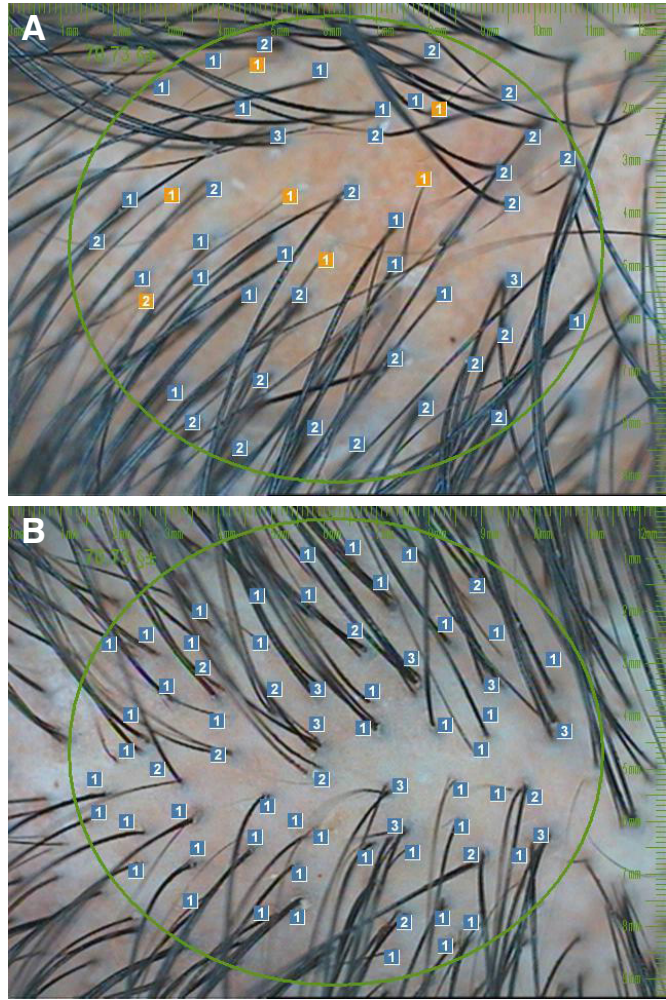

Figure 5: A: folliscope measurement of hair density before starting treatment; B: folliscope measurement of hair density after 4 months of nutritional correction and $2 \%$ minoxidil
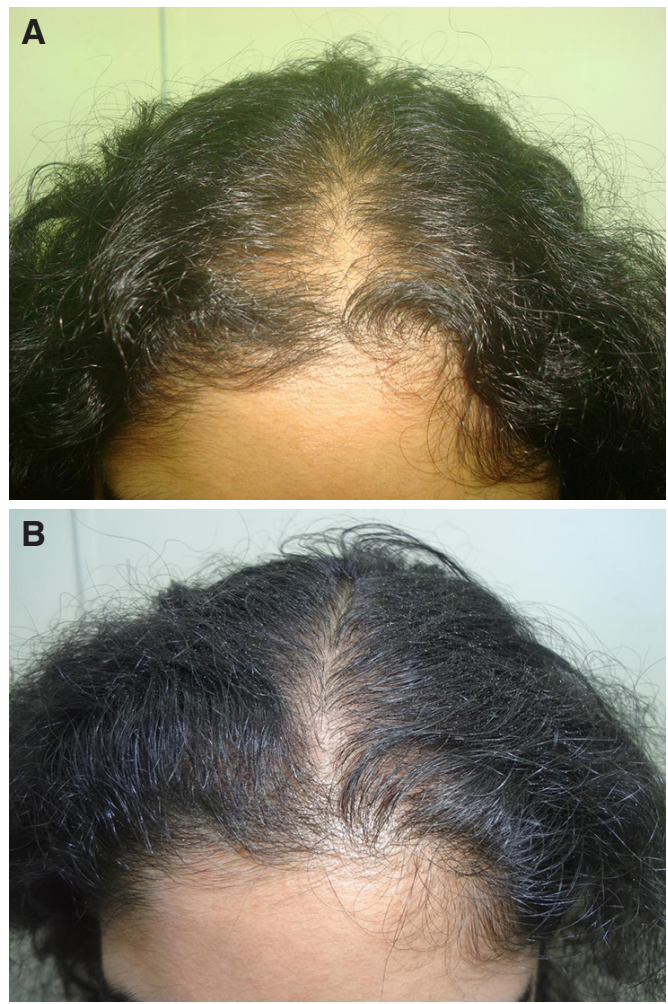

Figure 6: A: female pattern frontal hair loss day one before starting the treatment; $B$ : hair regrowth over frontal area after 6 months of $2 \%$ minoxidil and nutritional correction
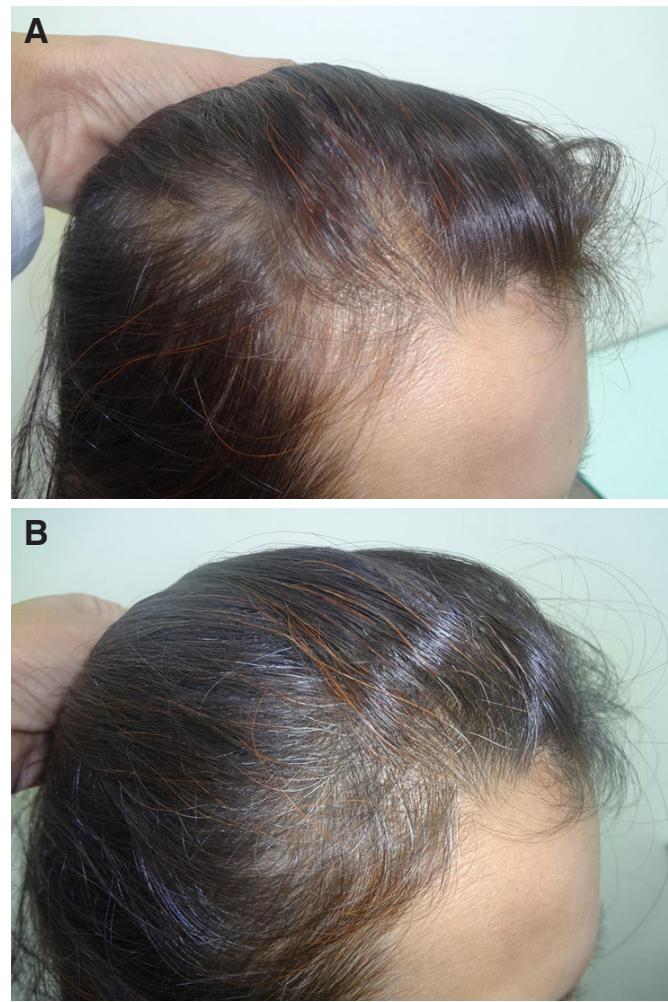

Figure 7: A: temporal receding and thinning in female patient day one before starting the treatment; B: hair regrowth over temporal area after 4 months of $2 \%$ minoxidil and nutritional treatment

improvement in density was $10 \%$ and the average calibre improved by $8 \%$. At the end of 1 year followup, the density had improved $16 \%$ and calibre had improved $12 \%$. There were $31 \%$ patients with no change in density or calibre at 6 months. This number reduced to $26 \%$ non-responders at the end of 1 year follow-up in women.

\section{Villus hair count}

Villus hair counts were recorded initially and compared over 2-month intervals for 1 year. The minimum and maximum villus hair counts for both the treatment groups initially were between $12-35 \%$, these reduced to between $5-24 \%$ at 4 months. The average counts again raised to $15-28 \%$ at 8 months and remained $10-$ $21 \%$ at the end of 1 year. Villus hair counts in control groups initially were between $14-38 \%$ and changed marginally at $11-40 \%$ at the end of 8 months and were between $16-34 \%$ at the end of one year.

\section{Global photography}

The overall rating in the control groups for both men and women were similar. The grading in the control group which started as no change at 2-4 months, improved to a noticeable change in $56 \%$ patients by the end of 1 year but none could be rated as good improvement. While the rating in the treatment groups 


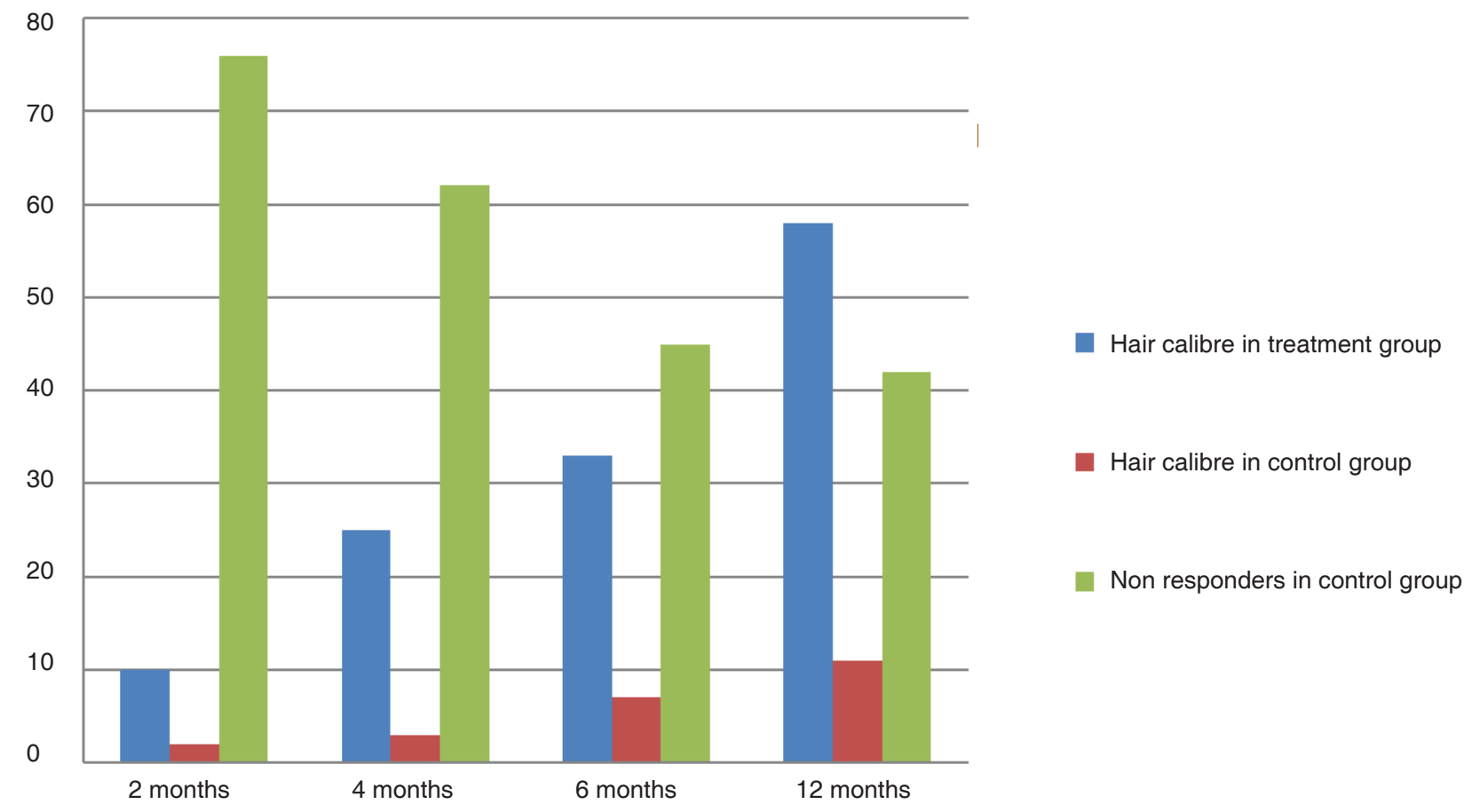

Figure 8: Hair calibre in women

for both men and women were similar, the improvement started as a noticeable change in 2 months for over $70 \%$ patients and progressed to good in all the patients by the end of 6 months, becoming very good by end of 1 year.

\section{Self-assessment scores}

Self-assessment in treatment groups TM and TW had scores of 4 seen in $70 \%$ men and $62 \%$ women noticing good hair growth within 4 months of commencing the therapy. Whereas $49 \%$ men and $74 \%$ women had a score of 5 , reporting that their hair stylist, their family and friends noticed the changes in their hair growth, thickness and quality at the end of one year.

Self-assessment in the control groups $\mathrm{CM}$ and $\mathrm{CW}$ for all patients were poor, below 3 . At the end of 1 year had $64 \%$ men and $71 \%$ women said that they looked the same, had continued hair loss and could not appreciate any improvement. There were $23 \%$ men and $14 \%$ women who noticed improvement in some areas and a few patients, $13 \%$ men and $15 \%$ women rated that they were worse than before.

\section{DISCUSSION}

Similar benefit as $68 \%$ reduction of hair fall in 1 month and $85 \%$ in 4 months were seen in the present study was reported by Beer et al. ${ }^{[69]}$ who studied the benefits from a keratin supplement with minerals and vitamins, which showed $12.5 \%$ reduction in hair loss over placebo at 1 month, $34.5 \%$ at 2 months and $34.4 \%$ reduction in hair loss at 3 months ${ }^{\left[{ }^{[69]}\right.}$. Rizer et al. ${ }^{[70]}$ who studied the benefit of marine protein supplement reported $20 \%$ reduced hair shedding within 4 months, while the placebo group had increased shedding by $50 \%$. Hair loss in control group continued the same in $41 \%$ and increased in $37 \%$ patients at the end of 4 months. Some relief from hair shedding seen in the control group may be due to the benefit of $2 \%$ minoxidil. A certain basic amount of steady hair fall did continue even in treatment group which can be expected to happen as per the natural hair cycle.

The improvement in density and calibre in both the male and female treatment groups were similar to improvement recorded by Beer et al. ${ }^{[69]}$ as per their criteria for evaluation of hair quality. Beer et al. ${ }^{[69]}$ studied the benefits from a supplement of keratin with minerals and vitamins which showed an improvement of $17.6 \%$ at 1 month, $35.3 \%$ at 2 months, and $47.1 \%$ at the end of 3 months ${ }^{[69]}$. Another study by Nicholas et al. ${ }^{[71]}$ comparing a supplement of green tea extract, omega 3 and 6 fatty acids, melatonin, cholecalciferol, betasitosterol, and soy isoflavones, over a period of 24 weeks (6 months), showed $4.9 \%$ improvement in terminal hair counts. Rizer et al. ${ }^{[70]}$ studied the benefit of marine protein supplement to find an overall $8 \%$ improvement in diameter for villus hair after 6 months. Rizer et al. ${ }^{[70]}$ did not compare terminal hair counts and hair calibre but suggested that further improvement could be possible if the supplements were continued for 1 year, 
as was observed to happen in the present study at the end of 1 year.

Improvement in hair density and calibre were found to begin early within 2 months in men and women in the treatment groups having nutritional supplements. Minoxidil stimulates hair growth and the addition of nutrients provides building blocks to ensure the sudden rapid cell division required at the initiation of anagen. Antioxidants provide a toxin free cellular environment which favours hair growth ${ }^{[24,25,72-74]}$. Use of different nutrients on different days prevents inter nutrient interactions and improves efficiency ${ }^{[75,76]}$. It also allows the use of wide variety of nutrients without the possibility of over dose or hyper vitaminosis ${ }^{[24,25,49,71,73]}$ as the hair care is required to continue for a long time to sustain good results.

In the control groups the hair growth started after 4-6 months which is the standard time frame required for the effect of finasteride and minoxidil ${ }^{[37-39,75]}$. The benefit with finasteride and minoxidil alone was slow and the maximum growth achieved in the control groups was below $50 \%$ of the improvement achieved in the treatment group. The results are similar to long term studies on the use of finasteride which have reported 48-59\% improvement with 41-52\% nonresponders $^{[35,37]}$ at the end of 1 year and $17 \%$ patients having deteriorated with hair loss more than the initial status after one year ${ }^{[35]}$.

Villus hair counts in our study initially reduced but were later found to rise. The initial reduction was because the villus hair had converted to terminal hair while the later rise was due to new hair growth induced with the treatment cycle and the counts finally stabilize as per the individual hair cycle and the individual turnover of hair fall and hair growth. Rizer et al. ${ }^{[70]}$ reported improvement in thickness of villus hair in $60 \%$ patients in their marine protein supplement study. Nicholas et al. ${ }^{[71]}$ reported $5.9 \%$ improvement of villus hair to terminal hair in 6 months of their study. The initial conversion of villus hair to terminal hair in our study was found to be higher, however, more villus hair were generated as new hair growth was induced. We could not establish a direct predictable correlation between reduction of villus hair counts and a proportionate improvement in hair growth.

Our study has noted early improvement in global photography evaluation within 2 months and reached higher grades of improvement over the period of completing the study. Similar evaluation was reported by Nicholas et al. ${ }^{[71]}$ with overall improvement of $80 \%$ on global photography out of which $40 \%$ were regarded as moderate and $10 \%$ excellent improvement in a period of 6 months. Our study being for 1 year, had the time for all the treated patients to achieve very good improvements.

Having self-assessment scores was a unique feature of our study. Patients appreciated the fact that they were allowed to express their concern and rate their results in the form of a score. The system also encouraged interaction of the patients with their friend, family and hair stylist who approved and agreed of noticeable changes in the hair. Thus the improvement was not only subjective.

\section{Side effects}

Irritation from minoxidil $2 \%$ solution causing burning, redness or itching after application was seen in $8 \%$ patients. This is mainly due to the propylene glycol and not due to minoxidil. Dryness of scalp after minoxidil $2 \%$ application was seen in $26 \%$ patients $^{[76]}$. Use of moisturizers on the scalp helped in these cases. Sexual side effects were reported by $4 \%$ of patients in the control group after the initial 2 months of therapy and $9 \%$ patients after 4 months of the therapy. These men had a loss of libido, decreased seminal volume and softer erections. Feeling gloomy, lack of enthusiasm, taking longer to complete the work at hand and being disinterested in meeting friends was reported by $7 \%$ patients. All these were patients having $1 \mathrm{mg}$ finasteride every day. Similar side effects which can be persistent, were reported by Irwig $^{[38]}$ and by Traish et al. ${ }^{[39]}$

The nutritional supplements caused gastric irritation, constipation, feeling of heaviness in the stomach, nausea or feeling of acidity in $7 \%$ women and $3 \%$ men. Though supplements were in low dose and spread over a 3 day cycle, 2 women doubted they had marginal weight gain due to the program. Rizer et al. ${ }^{[70]}$ in their study of marine protein supplement reported 3 patients in treatment group and three patients in the placebo group complaining of bloating and stomach discomfort. Lengg et al. ${ }^{[15]}$ in their study on nutritional therapy in telogen effluvium, reported gastric discomfort and weight gain. Sarris et al. ${ }^{[77]}$ in an individual study of multivitamins also reported of gastric discomfort in their study group. In the present study, it was noted that, the days when calcium and iron were included caused the most gastric problems. Avoiding supplements on empty stomach, dividing the supplements into 2 separate doses 1 supplement after breakfast or lunch and second supplement after dinner helped to ease the gastric symptoms.

\section{Beneficial effects}

Patients reported improved wellness on the low dose vitamin therapy. A female patient who preferred 
having regular blood test on her own, initially had a haemoglobin never above $9.6 \mathrm{gm}$ for past 10 years, reported a level of $11 \mathrm{gm}$ in 2 months and $14 \mathrm{gm}$ in 4 months. Patients had better energy levels, better stamina at work, improvement of small aches and pains, better skin, better nail growth, feeling of wellness, better grasping of studies in college, good sleep and waking up fresh, with the vitamin therapy. Similar benefits were also reported by Sarris et al. ${ }^{[77]}$ in their study of multivitamins.

In conclusion, finasteride was introduced for hair loss management by serendipity. The benefit from finasteride is seen clinically only after 6 to 9 months and long term studies have shown that it is effective only in $50-60 \%$ cases. DHT is not always raised in hair loss patients. Not high DHT but increased sensitivity of the hair follicles is the cause for miniaturization and hair loss. Instead of long term use of DHT blockers with the fear of side effects, we have studied a better option of strengthening the hair roots and promoting hair growth with nutritional supplements. The prospective controlled clinical trial shows that a low dose cyclical nutritional program planned to avoid nutrient interactions and improve synergy can be used to achieve consistent hair regrowth in men and women beginning within 2-4 months and continuing to benefit for 1 year. We can regrow hair safely, without our patients having to depend on finasteride which has been recently recognized to have persistent side effects.

\section{DECLARATIONS}

\section{Authors' contributions}

The author contributed solely to the paper.

\section{Financial support and sponsorship None.}

\section{Conflicts of interest}

There are no conflicts of interest.

\section{Patient consent}

All patients volunteered to give consent and made a choice to be enrolled in the conventional therapy group or the nutritional therapy group. All patients also agreed to complete the study for a period of one year.

\section{Ethics approval Not applicable.}

\section{REFERENCES}

1. Guarrera M, Rebora A. Anagen hairs may fail to replace telogen hairs in early androgenic female alopecia. Dermatology 1996;192:28-31.

2. Guarrera M, Rebora A. Kenogen in female androgenetic alopecia. A longitudinal study. Dermatology 2005;210:18-20.

3. Trüeb RM. Telogen Effluvium: Is there a need for a new classification? Skin Appendage Disord 2016;2:39-44.

4. Kligman AM. Pathologic dynamics of human hair loss. I. Telogen effuvium. Arch Dermatol 1961;83:175-98.

5. Rook A, Dawber R. Chapter 5. Diffuse alopecia: endocrine, metabolic and chemical influences on the follicular cycle. In: Rook A, Dawber R, eds. Diseases of the Hair and Scalp. Oxford, UK: Blackwell Science Publications;1982:115-45.

6. Headington JT. Telogen effluvium. New concepts and review. Arch Dermatol 1993;129:356-63.

7. Paus R, Cotsarelis G. The biology of hair follicles. $N$ Engl J Med 1999;341:491-7.

8. Liyanage D, Sinclair R. Telogen effluvium. Cosmetics 2016;3:13.

9. Chen W, Thiboutot D, Zouboulis CC. Cutaneous androgen metabolism: basic research and clinical perspectives. J Invest Dermatol 2002;119:992-1007.

10. Hoffmann R, Happle R. Current understanding of androgenetic alopecia. Part II: clinical aspects and treatment. Eur J Dermatol 2000;10:410-7.

11. Griffin JE, Wilson JD. The metabolic basis of inherited disease. The resistance syndromes: 5alpha reductase deficiency, testicular feminisation and related disorders. New York: McGraw-Hill; 1989. p. 1919-44.

12. Sawaya ME, Price VH. Different levels of 5alpha-reductase type I and II, aromatase, and androgen receptor in hair follicles of women and men with androgenetic alopecia. J Invest Dermatol 1997;109:296300 .

13. Birch MP, Messenger JF, Messenger AG. Hair density, hair diameter and the prevalence of female pattern hair loss. $\mathrm{Br} J$ Dermatol 2001;144:297-304.

14. Norwood OT. Incidence of female androgenetic alopecia (female pattern alopecia). Dermatol Surg 2001;27:53-4.

15. Lengg N, Heidecker B, Seifert B, Trüeb RM. Dietary supplement increases anagen hair rate in women with telogen effluvium: results of a double-blind, placebo-controlled trial. Therapy 2007;4:59-65.

16. Orme S, Cullen DR, Messenger AG. Diffuse female hair loss: are androgens necessary? Br J Dermatol 1999;141:521-3.

17. Cousen P, Messenger A. Female pattern hair loss in complete androgen insensitivity syndrome. Br J Dermatol 2010;162:1135-7.

18. Urysiak-Czubatka I, Kmieć ML, Broniarczyk-Dyła G. Assessment of the usefulness of dihydrotestosterone in the diagnostics of patients with androgenetic alopecia. Postepy Dermatol Alergol 2014;31:20715.

19. Wolff H, Fischer TW, Blume-Peytavi U. The diagnosis and treatment of hair and scalp diseases. Dtsch Arztebl Int 2016;113:377-86.

20. Trüeb RM. Pharmacologic interventions in aging hair. Clin Interv Aging 2006;1:121-9.

21. Goette DK, Odom RB. Alopecia in crash dieters. JAMA 1976;235:2622-3.

22. Fiedler VC, Gray AC. Chapter 10. Diffuse alopecia: telogen hair loss. In: Olsen EA, ed. Disorders of Hair Growth: Diagnosis and Treatment. 2nd ed. New York, NY: McGraw-Hill Publishing; 2003:303-20.

23. Sinclair RD, Dawber RP. Androgenetic alopecia in men and women. Clin Dermatol 2001;19:167-78.

24. Rajput R. Understanding hair loss due to air pollution and the approach to management. Hair Ther Transplant 2015;5:133.

25. Rajput RS. Benefit from vitamin therapy in smoker's hair. Hair Ther Transplant 2016;6:141.

26. Sinclair R. Diffuse hair loss. Int J Dermatol 1999;38 Suppl 1:8-18.

27. Lee WS, Lee HJ. Characteristics of androgenetic alopecia in asian. 
Ann Dermatol 2012;24:243-52.

28. Bahta AW, Farjo N, Farjo B, Philpott MP. Premature senescence of balding dermal papilla cells in vitro is associated with p16(INK4a) expression. J Invest Dermatol 2008;128:1088-94.

29. Harrison S, Sinclair R. Telogen effluvium. Clin Exp Dermatol 2002;27:389-95.

30. Ustuner ET. Cause of androgenic alopecia: crux of the matter. Plast Reconstr Surg Glob Open 2013;1:e64.

31. Kaufman KD. Androgens and alopecia. Mol Cell Endocrinol 2002;198:89-95.

32. Sawaya ME, Price VH. Different levels of 5alpha-reductase type I and II, aromatase, and androgen receptor in hair follicles of women and men with androgenetic alopecia. J Invest Dermatol 1997;109:296-300.

33. Chen W, Thiboutot D, Zouboulis CC. Cutaneous androgen metabolism: basic research and clinical perspectives. J Invest Dermatol 2002;119:992-1007.

34. Hoffmann R, Happle R. Current understanding of androgenetic alopecia. Part II: clinical aspects and treatment. Eur J Dermatol 2000;10:410-7.

35. Inadomi T. Efficacy of finasteride for treating patients with androgenetic alopecia who are pileous in other areas: a pilot study in japan. Indian J Dermatol 2014;59:163-5.

36. Price VH, Roberts JL, Hordinsky M, Olsen EA, Savin R, Bergfeld W, Fiedler V, Lucky A, Whiting DA, Pappas F, Culbertson J, Kotey P, Meehan A, Waldstreicher J. Lack of efficacy of finasteride in postmenopausal women with androgenetic alopecia. J Am Acad Dermatol 2000;43:768-76.

37. Kaufman KD, Olsen EA, Whiting D, Savin R, DeVillez R, Bergfeld W, Price VH, Van Neste D, Roberts JL, Hordinsky M, Shapiro J, Binkowitz B, Gormley GJ. Finasteride in the treatment of men with androgenetic alopecia. Finasteride male pattern hair loss study group. J Am Acad Dermatol 1998;39:578-89.

38. Irwig MS. Persistent sexual side effects of finasteride: could they be permanent? J Sex Med 2012;9:2927-32.

39. Traish AM, Hassani J, Guay AT, Zitzmann M, Hansen ML. Adverse side effects of $5 \alpha$-reductase inhibitors therapy: persistent diminished libido and erectile dysfunction and depression in a subset of patients. $J$ Sex Med 2011;8:872-84.

40. Eun HC. The involvement of ROS on androgen inducible TGF beta 1 regulation derived from dermal papilla cells; a suggestive implication of ROS on androgenetic alopecia. $J$ Am Academy Dermatol 2008;58:AB84.

41. Shin H, Yoo HG, Inui S, Itami S, Kim IG, Cho AR, Lee DH, Park WS, Kwon O, Cho KH, Won $\mathrm{CH}$. Induction of transforming growth factor-beta 1 by androgen is mediated by reactive oxygen species in hair follicle dermal papilla cells. BMB Rep 2013;46:460-4.

42. Trüeb RM. Molecular mechanisms of androgenetic alopecia. Exp Gerontol 2002;37:981-90.

43. Goette DK, Odom RB. Alopecia in crash dieters. JAMA 1976;235:2622-3.

44. Betsy A, Binitha M, Sarita S. Zinc deficiency associated with hypothyroidism: an overlooked cause of severe alopecia. Int J Trichol 2013;5:40-2.

45. Ozturk P, Kurutas E, Ataseven A, Dokur N, Gumusalan Y, Gorur A, Tamer L, Inaloz S. BMI and levels of zinc, copper in hair, serum and urine of Turkish male patients with androgenetic alopecia. J Trace Elem Med Biol 2014;28:266-70.

46. Jaworsky C, Kligman AM, Murphy GF. Characterization of inflammatory infiltrates in male pattern alopecia: implications for pathogenesis. Br J Dermatol 1992;127:239-46.

47. Young JW, Conte ET, Leavitt ML, Nafz MA, Schroeter AL. Cutaneous immunopathology of androgenetic alopecia. J Am Osteopath Assoc 1991;91:765-71.
48. Rajendrasingh JR. Role of non androgenic factors in hair loss and hair regrowth. J Cosmo Trichol 2017;3:118.

49. Rajput R. The concept of cyclical nutritional therapy for hair growth which can be applied for wellness. J Nutr Food Sci 2017;7:615.

50. Roughead ZK, Zito CA, Hunt JR. Inhibitory effects of dietary calcium on the initial uptake and subsequent retention of heme and nonheme iron in humans: comparisons using an intestinal lavage method. Am J Clin Nutr 2005;82:589-97.

51. Brown EB Jr, Dubach R, Moore CV. Studies in iron transportation and metabolism. XI. Critical analysis of mucosal block by large doses of inorganic iron in human subjects. J Lab Clin Med 1958;52:335-55.

52. Halliwell B. Antioxidants in human health and disease. Annu Rev Nutr 1996;16:33-50.

53. Halliwell B. The antioxidant paradox. Lancet 2000;355:1179-80.

54. Wang L, Li Q, Duan XL, Chang YZ. Effects of extracellular iron concentration on calcium absorption and relationship between $\mathrm{Ca} 2+$ and cell apoptosis in Caco-2 cells. World $J$ Gastroenterol 2005;11:2916-21.

55. Meydani M. Antioxidants in the prevention of chronic diseases. Nutr Clin Care 2002;5:47-9.

56. Rutkowski M, Grzegorczyk K. Adverse effects of antioxidative vitamins. Int J Occup Med Environ Health 2012;25:105-21.

57. Barzel US, Massey LK. E Excess dietary protein can adversely affect bone. J Nutr 1998;128:1051-3.

58. Linkswiler HM, Zemel MB, Hegsted M, Schuette S. Protein-induced hypercalciuria. Fed Proc 1981;40:2429-33.

59. Kerstetter JE, Allen LH. Dietary protein increases urinary calcium. $J$ Nutr 1990;120:134-6.

60. Itoh R, Nishiyama N, Suyama Y. Dietary protein intake and urinary excretion of calcium: a cross-sectional study in a healthy Japanese population. Am J Clin Nutr 1998;67:438-44.

61. Everts HB. Endogenous retinoids in the hair follicle and sebaceous gland. Biochim Biophys Acta 2012;1821:222-9.

62. Foitzik K, Spexard T, Nakamura M, Halsner U, Paus R. Towards dissecting the pathogenesis of retinoid-induced hair loss: all-trans retinoic acid induces premature hair follicle regression (catagen) by upregulation of transforming growth factor-beta2 in the dermal papilla. J Invest Dermatol 2005;124:1119-26.

63. Finner AM. Nutrition and hair: deficiencies and supplements Dermatol Clin 2013;31:167-72.

64. Rushton DH. Nutritional factors and hair loss. Clin Exp Dermatol 2002;27:396-404.

65. Guo EL, Katta R. Diet and hair loss: effects of nutrient deficiency and supplement use. Dermatol Pract Concept 2017;7:1-10.

66. Eritsland J. Safety considerations of polyunsaturated fatty acids. Am J Clin Nutr 2000;71:S197-201.

67. Harper AE. Origin of recommended dietary allowances--an historic overview. Am J Clin Nutr 1985;41:140-8.

68. Spirichev VB. Scientific rationale for the use of vitamins in the prophylactic and therapeutic purposes. Report 1. Lack of vitamins in the diet of modern human: reasons, consequences and correction. Vopr Pitan 2010;79:4-14. (in Russian)

69. Beer C, Wood S, Veghte RH. A clinical trial to investigate the effect of Cynatine HNS on hair and nail parameters. ScientificWorldJournal 2014;2014:641723.

70. Rizer RL, Stephens TJ, Herndon JH, Sperber BR, Murphy J, Ablon GR. A marine protein-based dietary supplement for subclinical hair thinning/loss: results of a multisite, double-blind, placebo-controlled clinical trial. Int $J$ Trichology 2015;7:156-66.

71. Nichols AJ, Hughes OB, Canazza A, Zaiac MN. An open-label evaluator blinded study of the efficacy and safety of a new nutritional supplement in androgenetic alopecia: a pilot study. J Clin Aesthet Dermatol 2017;10:52-6. 
72. Rajput RJ. Cyclical medicine for hair loss management and improved results in hair transplantation. Hair Transplant Forum Int 2008;18:208-10

73. Rajput RJ. Controversy: is there a role for adjuvants in the management of male pattern hair loss? J Cutan Aesthet Surg 2010;3:82-6.

74. Rajput R. Improvement in hair loss and better hair quality with vitamin therapy in monilethrix. $J$ Cosmo Trichol 2016;2:113.

75. Rajput R. Hair Loss due to electromagnetic radiation from overuse of cell phone. J Cosmo Trichol 2016;2:114.
76. Olsen EA, Dunlap FE, Funicella T, Koperski JA, Swinehart JM, Tschen EH, Trancik RJ. A randomized clinical trial of 5\% topical minoxidil versus $2 \%$ topical minoxidil and placebo in the treatment of androgenetic alopecia in men. J Am Acad Dermatol 2002;47:377-85.

77. Sarris J, Cox KH, Camfield DA, Scholey A, Stough C, Fogg E, Kras M, White DJ, Sali A, Pipingas A. Participant experiences from chronic administration of a multivitamin versus placebo on subjective health and wellbeing: a double-blind qualitative analysis of a randomised controlled trial. Nutr J 2012;11:110. 